\title{
Educational Intervention: A Useful Tool for Assessing Knowledge of Medical Students Regarding National Vector Borne Disease Control Programme
}

\author{
Patil, R.S. ${ }^{1}$, Bogam, R.R. ${ }^{2}$, Gothankar, J.S. ${ }^{3}$, Sane, S. ${ }^{4}$
}

\begin{abstract}
Background: Quizzes are considered one of the most effective methods for promoting self-learning and motivating students to be more attentive during teaching activities. Understanding of a National Health Programme is necessary for medical students not only because it is a part of the medical curriculum, but also to provide the same knowledge to others for control of vector borne diseases.
\end{abstract}

Objective: Present study aimed to assess the effectiveness of a quiz on knowledge of undergraduate MBBS medical students regarding National Vector Borne Disease Control Programme.

Methods: All seventh semester medical undergraduates, $(n=145)$ of Bharati Vidyapeeth Medical College, Pune participated in the quiz and completed pre and post intervention questionnaires. The data was analyzed by using McNemar's test.

Results: Out of the ten questions, significant improvement in knowledge was found after the quiz in seven questions while for three questions though knowledge was increased it was not statistically significant. The response of students for insecticide used in insecticidal impregnated bed nets, which was zero in the pre-test increased to $6.9 \%$ in the post-test.

Conclusion: Present study showed significant improvement in medical student's knowledge regarding the National Vector Borne Disease Control Programme as a result of a quiz based Educational intervention.

Keywords: Quiz, Undergraduate, Education

\section{Introduction}

Mosquitoes, flies, ticks and bugs may be a threat to your health and that of your family - at home and when travelling. This is the message of this year's World Health Day, on 7th April 2014 with slogan 'Small bite, big threat'.

\footnotetext{
${ }^{1}$.Assistant Professor, Department of Community Medicine,Bharati Vidyapeeth University Medical College, Pune,Maharashtra,India.

${ }^{2}$ Assistant Lecturer, Department of Community Medicine,Bharati Vidyapeeth University Medical College, Pune, Maharashtra, India.

3. Professor and Head, Department of Community Medicine,Bharati Vidyapeeth University Medical College, Pune, Maharashtra, India

4. Assistant professor, statistician, Department of Community Medicine, Bharati Vidyapeeth University Medical College, Pune, Maharashtra, India

Corresponding Author:

Dr.Reshma S. Patil, A-106, Kanchanban Phase - II, Shivtirthnagar, Kothrud , Pune, Maharashtra, 411038, India

Email: reshsu2001@yahoo.co.in
}

Vector borne diseases (malaria, dengue, chikungunya, lymphatic filariasis, Japanese Encephalitis) are highly rampant, leading to a high morbidity and mortality (World Health Day 2014). The National Vector Borne Disease Control Programme (NVBDCP) is an essential programme that aims at prevention and control by early diagnosis, complete treatment and integrated vector management. The NVBDCP envisages a well informed and self-sustained, healthy India with equitable access to quality health care. The programme activities are in tandem with the National Health Policy (2002) and National Rural Health Mission (NRHM) goals as well as the Millennium Development Goal (MDG) of halting and reversing the incidence of malaria and other vector borne diseases by the year 2015 (National Project Implementation Plan 2008-2013).

One of the challenges for medical teachers is to make students understand the practical aspects of the National Health Programmes. Among the several methods of learning and 
teaching, quizzes are considered one of the most effective. During the preparatory phase prior to the quiz, students are encouraged to study more intensively and post-quiz it may generate interest in several topics that may otherwise be ignored. Thus it promotes selflearning and motivates students to be more attentive. In addition, a quiz may be regarded as a form of assessment which can potentially strengthen knowledge that will lead to improved expertise (Gupta et al., 2013). The present study was attempted to assess the effectiveness of a simple intervention in the form of a quiz competition on the knowledge of undergraduate students regarding NVBDCP.

\section{Material and Methods}

This study was conducted in a Private Medical College, in India among the seventh semester undergraduate MBBS students during their morning practical posting in the department of Community Medicine between, August 2013 to December 2013. A total of 145 undergraduates participated in study. Written permission was obtained from the participants after explaining the purpose of study and also anonymity of participants was guaranteed.

The study was conducted in three phases:

\section{I). Pre-intervention Phase}

A structured pre-tested self-administered questionnaire consisting of 10 questions related to NVBDCP were distributed to all 145 students. These questions were part of the actual quiz. They were allowed 10 minutes to complete pre-test questionnaire under strict supervision.

\section{II). Intervention Phase}

Five teams were selected on voluntary basis as participant teams. Each team consisted of one male and one female student. Remaining students participated as target audience. Quiz competition was conducted by Faculty members from department of Community Medicine. One of the students from target audience was appointed to assign scores for the teams.

Total of 70 questions including 10 questions of the pre-test were covered during quiz. Four rounds were conducted in the quiz. The first round being 'Answer in one word' had 2 subrounds. It was followed by 'multiple choice questions' in four options were given, with one correct answer. Third round was 'round of abbreviations'. The last round was 'rapid fire round' in which students were supposed to answer maximum number of questions. Time allotted for answering the question was 1 minute. At the end of each round, both correct and incorrect answers were discussed with all participants and audience.

A common marking system was assigned for all four rounds; i.e. 5 marks for a correct answer and zero marks for an incorrect answer. One extra mark was awarded for the team who gave a correct answer for passed questions. The audience was also involved actively in the quiz competition. A separate set of questions was asked from them. Thus the quiz involved not only the participants of the competition but also the students in the audience who passively participated in it. The total duration for intervention phase was two hours.

\section{III). Post -intervention Phase}

At the end of the programme, the same questionnaire was distributed to all students and responses were collected. It was followed by prize distribution for all winning teams and runner up teams.

\section{Data Analysis:}

The data was entered in Microsoft Office Excel Sheet and analyzed by using Mcnnemars Test.

\section{Results}

In the present study, out of 145 students, 88 $(60.68 \%)$ were female. All students were ages 19-24 years of age. Table 1 summarizes the responses to the pre and post intervention questionnaire. Out of the total ten questions asked in pre intervention, in six answers we found statistically significant change in student's knowledge in post intervention. Question numbers 1, 2 and 6 showed that though there was improvement in knowledge it was statistically insignificant. Not a single student had an idea of which insecticide is commonly used in insecticidal impregnated bed nets $(Q 4)$ before intervention, but after intervention $6.9 \%$ students gave the correct response.

Out of 145 students, 135 (93.1\%) answered correctly with regard to the meaning of NVBDCP in the pretest and 132 answered correctly in the post-test. Among those who had answered correctly in the pre-test, 122 gave the same answer in the post-test and those who had given the wrong answer in the pre-test i.e 10 students, gave the correct answer in the post test.(Q1) 
Eighty five (58.63\%) students answered correctly the year by which lymphatic filariasis is to be eliminated in pre-test and 91 (62.75\%) answered correctly in post-test. Thirty five (58.33\%) students who gave wrong answer in pre-test, answered correctly in post-test while $25(41.67 \%)$ students answered incorrectly in both pre and post -tests. Also post intervention it was found that the frequency of students for giving wrong answer has been reduced from $60(41.37 \%)$ to $54(37.24 \%)$ which was found statistically insignificant. (Q 2)
Availability of larvivorous fish free of cost was known to $77(48.27 \%)$ students in the pre-test and it increased to 101 in the post-test $(69.65 \%)$ students. Out of all the students who had answered correctly in the pre-test, 52 $(67.53 \%)$ gave the same answer in the posttest and from those who gave the wrong answer in the pre-test 49 (72.06\%) students, gave the correct answer in the post-test. In addition the number of students with incorrect answers reduced from $68(46.89 \%)$ to 44 (30.34\%). This shows an improvement in students' knowledge post intervention which was statistically significant. (Q 3)

Table 1: Student's responses regarding NVBDCP according to the questions $(n=145)$

\begin{tabular}{|c|c|c|c|c|c|}
\hline \multirow{2}{*}{ Questions } & \multirow{2}{*}{$\begin{array}{l}\text { Pre } \\
\text { Test }\end{array}$} & \multicolumn{2}{|c|}{ Post Test } & (\%) & \multirow{2}{*}{$P$ value } \\
\hline & & Yes & No & TOTAL & \\
\hline \multirow{2}{*}{$\begin{array}{l}\text { 1. Students knowledge on } \\
\text { full form of NVBDCP }\end{array}$} & Yes & 122(90.37) & 13(9.63) & $135(93.1)$ & \multirow[t]{2}{*}{$>0.05 \mathrm{NS}$} \\
\hline & No & $10(100)$ & $0(0)$ & $10(6.89)$ & \\
\hline \multirow{2}{*}{$\begin{array}{l}\text { 2. As per NVBDCP } \\
\text { lymphatic filariasis is to } \\
\text { be eliminated by } 2015\end{array}$} & Yes & $56(65.88)$ & $29(34.12)$ & $85(58.63)$ & \multirow[t]{2}{*}{$>0.05 \mathrm{NS}$} \\
\hline & NNO & $35(58.33)$ & $25(41.67)$ & $60(41.37)$ & \\
\hline \multirow{2}{*}{$\begin{array}{l}\text { 3. Availability of } \\
\text { Larvivorous fish free of } \\
\text { cost }\end{array}$} & Yes & $52(67.53)$ & $25(32.47)$ & $77(48.27)$ & \multirow[t]{2}{*}{$<0.05 \mathrm{~S}$} \\
\hline & No & $49(72.06)$ & $19(27.94)$ & $68(46.89)$ & \\
\hline \multirow{2}{*}{$\begin{array}{l}\text { 4.Insecticide commonly } \\
\text { used in insecticidal } \\
\text { impregnated bed nets }\end{array}$} & Yes & 0 & 0 & 0 & \\
\hline & No & $10(6.9)$ & $135(93.1)$ & 145 & \\
\hline \multirow{2}{*}{$\begin{array}{l}\text { 5.Passive surveillance of } \\
\text { malaria is done by } \\
\text { doctors }\end{array}$} & Yes & $8(40)$ & $12(60)$ & $20(13.79)$ & \multirow[t]{2}{*}{$<0.05 \mathrm{~S}$} \\
\hline & No & $50(40)$ & $75(60)$ & $125(86.21)$ & \\
\hline \multirow{2}{*}{$\begin{array}{l}\text { 6.Under NVBDCP only } \\
\text { Falciparum detection kits } \\
\text { are available free of cost }\end{array}$} & Yes & $59(64.84)$ & $32(35.16)$ & $91(62.75)$ & \multirow[t]{2}{*}{$>0.05 \mathrm{NS}$} \\
\hline & No & $36(66.67)$ & 18(33.33) & $54(37.25)$ & \\
\hline \multirow{2}{*}{$\begin{array}{l}\text { 7. Oral artemisinin } \\
\text { monotherapy is banned } \\
\text { in India }\end{array}$} & Yes & $49(73.13)$ & $18(26.87)$ & $67(46.20)$ & \multirow[t]{2}{*}{$<0.05 \mathrm{~S}$} \\
\hline & No & $62(79.49)$ & $16(20.51)$ & $78(53.80)$ & \\
\hline \multirow{2}{*}{$\begin{array}{l}\text { 8. NVBDCP programme } \\
\text { merged under the } \\
\text { umbrella of NRHM }\end{array}$} & Yes & $110(82.71)$ & $23(17.29)$ & 133(91.73) & \multirow[t]{2}{*}{$<0.05 \mathrm{~S}$} \\
\hline & INO & $8(66.67 \%)$ & $4(33.33 \%)$ & $12(8.27)$ & \\
\hline \multirow[t]{2}{*}{$\begin{array}{l}\text { 9. Under NVBDCP } \\
\text { meaning of RDT }\end{array}$} & Yes & $23(69.70)$ & $10(30.30)$ & $33(22.76)$ & \multirow[t]{2}{*}{$<0.05 \mathrm{~S}$} \\
\hline & No & $53(47.32)$ & $59(52.68)$ & $112(77.24)$ & \\
\hline \multirow{2}{*}{$\begin{array}{l}10 . \text { The three pronged } \\
\text { strategy for prevention } \\
\text { and control of vector } \\
\text { borne diseases under } \\
\text { NVBDCP }\end{array}$} & Yes & $2(11.76)$ & $15(88.24)$ & 17(11.72) & \multirow[t]{2}{*}{$<0.05 \mathrm{~S}$} \\
\hline & No & $48(37.50)$ & $80(62.50)$ & $128(88.28)$ & \\
\hline
\end{tabular}


Out of 145 students, only 20 (13.79\%) students answered correctly in the pre-test that passive surveillance is done by doctor and $58(40 \%)$ students answered correctly in postincluding 8 students (40\%) who answered correctly in pre-test and 50 who answered incorrectly. (40\%) Thus as the frequency of students giving the correct answer increased, the frequency of wrong answers reduced and it was found to be significant statistically. (Q 5)

Availability of Falciparum detection kits under NVBDCP was known to 91 (62.75\%) students in the pre-test which increased in post-test to 95 (65.51\%).Though the study findings showed an increase in the students' knowledge it was not found to be significant statistically . (Q 6)

Sixty seven (46.20\%) students answered correctly in the pre-test regarding oral artemisinin therapy being banned in India while after intervention the number of students giving the correct answer increased to 111 (76.55\%). That means that 49 who gave the correct answer in the pre-test $(73.13 \%)$ gave the same answer in post-test and 62 $(79.49 \%)$ with the incorrect answer in the pretest, gave the correct answer in post-test. This improvement in knowledge of students was found to be statistically significant. (Q 7)

A total of 110 (82.71\%) students gave the correct answer in pre-test and post-test that NVBDCP is merged under the umbrella of National Rural Health Mission. Out of 145 students, 133 (91.73\%) answered correctly in pre-test and $118(81.38 \%)$ answered correctly in post-test. (Q 8)

The number of students giving the correct meaning of RDT increased from 33(22.76\%) students to 76 (52.41\%) students after intervention and the frequency of answering incorrectly was decreased from pre-test to post-test i.e. from 112 (77.24\%) to 69 $(47.59 \%)$ which was found to be statistically significant. (Q 9)

The three pronged strategy for prevention and control of vector borne diseases was found to be difficult for students to answer and only 17 $(11.72 \%)$ out of 145 answered correctly in the pre-test and after intervention this number significantly raised to 50 (34.48\%). In addition, the number of students answering incorrectly reduced to $95(65.52 \%)(Q 10)$

\section{Discussion}

The NVBDCP is one of the most comprehensive and multifaceted public health activities in India and concerned with the prevention and control of vector borne diseases namely malaria, filarial, dengue, kala-azar, chikungunya and Japanese encephalitis that have re-emerged as epidemics after more than three decades (Kishore, 2012). Looking at the heavy burden of these diseases, understanding of the programme by the students is essential, as students can act as effective agents for change of health in their peer groups, families and communities if they learn National Health Programmes with interest (Deepthi et al., 2014).

Students stay interested and learn more in class when teachers use many different techniques to involve them in the learning process. Active learning strategies serve as useful educational tools only when all students participate all of the time (Center for Teaching and Assessment of Learning). Voluntary participation opportunities in academic activities such as quizzes provide a platform for learning and self-assessment for students. These activities are not high-stakes, yet are challenging for the participants possibly because of the presence of an audience. The results from the study done by Goud et al. (2014) in undergraduate first year students suggested that the integrated quizzes stimulate self and collaborative learning.

Data in our study indicates students read and discussed the NVBDCP before and after the quiz. Similar findings were noted by Gupta et al. (2013) in their study conducted amongst post graduate students using an audiovisual quiz.

Overall we have found a drastic change in student's knowledge regarding NVBDCP after a simple intervention like a quiz. In most of the questions we found that as the students' knowledge increased, the frequency of incorrect answers decreased, which states the effect of active participation of students in interventional teaching activities. This emphasizes that a quiz can be a very effective teaching method rather than a routine didactic lecture series for imparting knowledge amongst students. La Beaud et al. (2009) and Yasuoka et al. (2006) also reported significant knowledge improvement in response to the intervention.

In our study, for question number 8, the decrease in knowledge of students post intervention was noted. This could be due to student's attitude of selecting answers haphazardly without much thinking which is 
commonly seen in this age group (Q 8, Table 1). Tobgay et al. (2013) reported despite an increase in mean score for knowledge, the mean score for attitude and practice decreased during post-intervention as compared to pre-intervention in his study done in Bhutan.

The most important finding from this study was that the simple educational intervention was useful to sensitize the undergraduate students which had a significant positive impact on their knowledge regarding the National Vector Borne Disease Control Programme. Thus quizzes act as a tool to encourage and monitor student's progress (Fenderson et al., 1996) and they are a great "vehicle" for higher quality student teacher communication. (Poljičanin et al., 2009).

\section{Conclusion}

The findings from this study corroborate that, simple interventions such as quizes can be utilized as an effective means for improving knowledge and creating interest in the National Health Programme amongst undergraduate medical students. Further studies are needed to see the long-term effect and sustainability of such interventions as such type of studies have not been done before in the said population.

\section{References}

Center for Teaching and assessment of learning. [Online] Available from http://cte.udel.edu /publications /hand book-graduateassistants/student-participation-learning-aboutactive-learning.html [accessed 22 April 14]

Deepthi, R., Kumar, N.S.J., Kamath, B.T.P \& Rajeshwari, H. (2014) Participatory school health education on vector-borne diseases: engaging children as change agents, International Journal of Health Promotion and Education, 52, 2, pp.68-77.
Fenderson, B.A, Fishback J, Damjanov I. (1996) Weekly mini-examinations (quizzes) based on extended-matching questions as a means for monitoring medical student performance, Croatian Medical Journal, 37, pp.283-287.

Gaud, B.K.M, Begum, G. S (2014).Integrated Quiz Competition: A Innovative Method of Teaching and Learning in Undergraduate First Year Medical Course at RAKMHSU, UAE, British Journal of Medicine \& Medical Research, 4, 20, pp. 3755-3766

Gupta, R, Gupta, L. K., Patil, V. \& Rehan, H.S. (2013) In-training assessment of postgraduate students in pharmacology using an audiovisual quiz, Journal of Contemporary Medical Education, 1, 2, pp.126-131.

Kishore, J. (2012) National health programmes of India, $10^{\text {th }}$ ed,New Delhi: Century publication

La Beaud, A.D., Glinka, A., Kippes, C \& King C.H (2009) School-Based Health Promotion For Mosquito-Borne Disease Prevention in Children, Journal of Pediatrics, 155, 4, pp.590-592.

National Project Implementation Plan (2008-2013) [Online] Available from http://nvbd cp.gov.in/Doc/PIP.pdf (accessed on 12/4/2014)

Poljičanin, A., Čarić, A., Vilović, K., Košta, V., Marinović Guić, M., Aljinović, J \& Grković I (2009) Daily Mini Quizzes as Means for Improving Student Performance in Anatomy Course, Croatian Medical Journal, 50, pp.55-60.

Tobgay, T., Pem, D., Dophu, U., Dumre, S.P., Bangchang, K.N \& Torres, C, E. (2013) Community-directed educational intervention for malaria elimination in Bhutan: quasiexperimental study in malaria endemic areas of Sarpang district, Malaria Journal, 12, p.132.

Yasuoka, J., Mangione, T.W. \& Levins, A.S.R (2006) Impact of education on knowledge, agricultural practices, and community actions for mosquito control and mosquito-borne disease prevention in rice ecosystems in Srilankaam, American journal of Tropical medicine and hygiene 74, 6, pp.1034-1042. 